\title{
TEOLOGI KEHADIRAN DALAM TABERNAKEL
}

\author{
Jannen R. Pangaribuan
}

\begin{abstract}
This writing is about the presence of God that continuous for His people by His grace and His sovereign will especially in the Old Testament that also shows God wants to have fellowship with His people's and as a manifestation of His authority on everything. Taking the Old Testament as a unity in continuation with New Testament in salvational history (heilsgeschicte) that has not final yet till the coming of the Messiah for the second time at the last day - the unity of $O T$ and NT could be seen in the centre theme of both testaments that is Imanuel. God manifest His presence's in Tabernacle and the temple, the presence that brings everything before Him, then everything is uncovered before Him - He is the Judge to whom we must give account. We live for Him, and all the glory only to God alone.
\end{abstract}

Key Words: Old Testament and New Testament, Covenant, Immanuel, Presence, Tabernacle

\begin{abstract}
Abstrak
Tulisan ini adalah tentang kehadiran Allah yang terus-menerus bagi umat-Nya oleh anugerah dan kehendak-Nya yang berdaulat, khususnya dalam Perjanjian Lama untuk bersekutu dengan umat itu dan wujud pemerintahan-Nya atas segala sesuatu. Perjanjian Lama diterima sebagai suatu kesatuan dalam keberlanjutan dengan Perjanjian Baru dalam sejarah keselamatan Allah (heilsgeschicte), merupakan suatu sejarah yang belum final hingga kedatangan Mesias kedua kali pada akhir zaman (eschaton) kesatuan PL dan PB itu dilihat dengan pendekatan tema inti Imanuel. Allah menyatakan kehadiran-Nya dalam Tabernakel dan Bait Allah, ketika Allah hadir maka segala sesuatu ada di hadapan-Nya, karena itu segala sesuatu pun terbuka di hadapan-Nya - Dia Hakim yang kepadaNya kita harus mempertanggungjawabkan segala sesuatu yang kita perbuat. Bagi Dia kita hidup, dan segala kemuliaan hanya bagi Tuhan saja.
\end{abstract}

Kata-kata Kunci: Perjanjian Lama, Perjanjian Baru, Imanuel, Kehadiran, Tabernakel 


\section{LATAR BELAKANG}

Tabernakel adalah pokok yang penting dalam Alkitab, tidak kurang 50 fasal dalam Alkitab (Perjanjian Lama dan Perjanjian Baru) menuliskan hal Tabernakel (Kemah Suci) ini secara khusus. ${ }^{1}$ Dan telah banyak usaha untuk melihat signifikansinya bagi iman Kristiani. Salah satu buku yang sangat memberikan penghargaan terhadap Tabernakel ini, telah ditulis pada akhir abad 19 oleh seorang Yahudi Kristen bernama William Brown yang mengatakan bahwa memang Tabernakel, imam-imamnya, ritus-ritusnya, pengorbananpengorbanannya telah berlalu, tetapi lukisan dan sejarahnya tinggal tetap. ${ }^{2}$ Dan tulisan kudus itu menyaksikan Yesus Kristus - yang berkata tentang Musa, "Ia menulis tentang Aku." Brown melihat dalam mempelajari Tabernakel, dan apa yang menjadi tujuannya, akan menambah pengetahuan akan keagungan penebusan.

Di Indonesia Tabernakel sebagai suatu pengajaran yang mengandung maksud dan rencana Allah bagi gereja dipopulerkan oleh F. G. van Gessel (1892-1958) sejak tahun 1923. ${ }^{3}$ Beliau memandang tujuan Kemah Suci dibangun adalah agar Allah tinggal di antara umat-Nya. ${ }^{4}$

Dalam beberapa dekade terakhir pemahaman yang diakui sebagai meneruskan apa yang diajarkan oleh F. G. van Gessel diperkenalkan kembali oleh Jusuf BS yang juga mengatakan bahwa tujuan dari pembangunan Tabernakel adalah supaya Allah berada di tengah-tengah bani Israel dengan tujuan supaya ada penyertaan Allah atas umat-Nya. ${ }^{5}$ Saat ini Kemah Suci dengan segala peralatannya tidak ada lagi selain catatan-catatan yang tertulis tentangnya, menurut Jusuf BS urgensi dari Tabernakel adalah dengan melihatnya sebagai Firman Allah yang di dalamnya ada arti-arti tersembunyi dalam keteranganketerangan Kemah Suci itu. Dengan pemahaman seperti ini, pendekatannya mengakomodasi penafsiran alegoris.

Pendekatan lainnya dalam memahami Tabernakel ini yang telah banyak ditempuh adalah dengan pendekatan tipologis. Misalnya Harris yang mengatakan "Kemah Suci sebagai suatu tempat bagi jalan Allah memberikan kehadiran Ilahi. Di situlah kemuliaan Shekinah akan berdiam. Di situ Allah akan bertemu

${ }^{1}$ C. W. Slemming, Dibangun Menurut Pola Sorgawi (Surabaya: Yakin, 20100), 11. Buku Asli berjudul Make According to Pattern (1938).

${ }^{2}$ William Brown, The Tabernacle: Its Priests and Its Services, Updated Edition (Peabody Massachusetts: Hendrickson Publishers, 1996), 3. Buku asli: The Tabernacle: Its Priests and Its Services, Described and Cosidered in Relation to Christ and the Church, diterbitkan oleh Oliphant, Anderson \& Ferrier, Edinburg \& London, 1899.

${ }^{3}$ Gersom Soetopo, Tabernakel (Jawa Timur: STT Lawang, 2003), $i$.

${ }^{4}$ F. G. van Gessel, The Tabernacle, BTI Holland (tidak dipublikasikan), 3.

${ }^{5}$ Jusuf BS, Kemah Suci, Edisi III (Oktober 1993), 20. 
dengan umat-Nya." Harris memahami bahwa Tabernakel memiliki lambang-lambang yang diantisipasi dalam Perjanjian Baru, misalnya peralatan dalam Tabernakel seperti Mezbah Tembaga yang menggambarkan Golgota. Bejana Pembasuhan melambangkan penyucian dengan memakai Firman Allah, dst.

Wolf menyoroti penekanan yang berlebihan terhadap arti tipologis Kemah Suci ini $^{7}$, walaupun ia sendiri mengakui bahwa simbolisme dari bangunan yang unik ini melimpah dan penuh arti. Ia menyetujui maksud mendasar dari Kemah Suci menggambarkan hasrat Allah untuk tinggal di tengah-tengah umat-Nya (Kel. 25:8). Kemah Suci mengantisipasi inkarnasi Kristus sebagaimana dikatakan dalam Yoh. 1:14, "Firman itu ... diam di antara kita" atau lebih harafiah lagi, "Firman itu... berkemah di antara kita." Wolf menambahkan bahwa kemuliaan yang dilihat adalah Kemuliaan Kristus dalam bentuk mukjizat-mukjizat yang diadakan-Nya dan kebangkitan-Nya. Demikian juga dengan Merrill yang tanpa ragu mengakui bahwa Tebrnakel dan perabot-perabotnya memiliki makna tipologis yang agung, namun menambahkan bahwa penafsirannya sering berlebihan: "though interpreters sometimes read far more into it than can be justified by sound hermeneutics and biblical theology."

Memang jelas bahwa penafsiran tipologis dibedakan dengan penafsiran alegoris seperti yang dinyatakan dalam defenisi oleh J. Gerhard: "Tipologi terdiri dari perbandingan dari fakta-fakta. Alegori tidak berkaitan dengan faktafakta tetapi dengan kata-kata dari mana menarik pengajaran yang tersembunyi dan berguna. ${ }^{9}$

Perlu diperhatikan peringatan Greidanus terhadap penafsiran alegoris bahwa walaupun penafsiran alegoris tidak menyangkal sejarah penebusan, sejarah itu tidak ada gunanya dalam menafsirkan Kitab Suci secara alegoris. ${ }^{10}$ Sebaliknya penafsiran tipologis menuntut adanya sejarah penebusan karena analogi peningkatan antara penggambaran dan penggenapannya terjadi dalam

${ }^{6}$ Ralph W. Harris, Lambang-lambang di Perjanjian Lama (Malang, Jawa Timur: Penerbit Gandum Mas, 2006), 39. Buku Asli: Old Testament Types, diterbitkan Gospel Publishing House, 1965.

${ }^{7}$ Henry Wolf, Pengantar Pentateukh (Malang: Penerbit Gandum Mas, 2004), 216.

${ }^{8}$ Pandangan yang sama ditunjukkan oleh Eugene H. Merril, An Historical Survey of Old Testament, Second Edition (Grand Rapids, Michigan: Baker Book House, 2002), 143-44.

${ }^{9}$ Sebagaimana dikutip dari Goppelt Leonhard, Typos, the typological interpretation of the Old Testament in the New (Grand Rapids: Wm. B. Eerdmans Publishing Co.,1939),7.

${ }^{10}$ Sidney Greidanus, Preaching Christ from the Old Testament-Mengkhotbahkan Kristus dari Perjanjian Lama, (Bandung: Yayasan Kalam Hidup, 2009), 134. 
sejarah penebusan. Ia mengutip KJ. Woolcombe ${ }^{11}$ bahwa penafsiran tipologis adalah usaha mencari hubungan antara peristiwa-peristiwa, orang atau sesuatu dalam batas-batas sejarah dari suatu penyataan, sedangkan alegorisme adalah usaha mencari makna tersembunyi yang mendasari makna utama dan tampak jelas dari suatu teks.

Namun ada juga keterbatasan dari pendekatan tipologis dalam memahami Perjanjian Lama khususnya Tabernakel, sebab penafsiran tipologis "membaca kembali" (reading back) ${ }^{12}$ dengan sudut pandang Perjanjian Baru sehingga tidak dapat melihat esensi Tabernakel itu apa adanya sebagai bagian dari Perjanjian Lama. Pada dasarnya teks Alkitab mempunyai satu arti, yakni arti harfiah, yang ditemukan melalui penelitian bahasa dan sejarah. Tipologi bukanlah eksegesis atau tafsiran teks melainkan penelitian tentang hubungan antara peristiwa-peristiwa, pribadi-pribadi dan pranata-pranata yang dicatat dalam teks-teks Alkitab. ${ }^{13}$

Karena itu perlu ada pendekatan biblika yang dapat ditempuh dalam melihat signifikansi Tabernakel dan maknanya sesuai dengan teks sebagai pewahyuan yang progresif di dalam satu kesatuan yang berkelanjutan dengan Perjanjian Baru ${ }^{14}$ sehingga kedua perjanjian itu dapat dipandang secara adil, dan juga dapat menunjukkan relevansi Tabernakel atau Perjanjian Lama dalam penyataannya yang bersifat progresif bagi iman Kristiani tanpa harus "mendevaluasi atau menafsirkannya ulang." Untuk itu penulis mendekatinya secara blibika dengan menetapkan inti atau pusat ${ }^{15}$ dari Perjanjian Lama yang memiliki keberlanjutannya di dalam Perjanjian Baru hingga eskaton (akhir

${ }^{11}$ Sidney Greidanus, Preaching Christ from the Old Testament-Mengkhotbahkan Kristus dari Perjanjian Lama, 134.

${ }^{12}$ E. Earle Ellis dalam Kata Pengantar Goppelt Leonhard, Typos, the typological interpretation of the Old Testament in the New (Grand Rapids: Wm. B. Eerdmans Publishing Co., 1939), xiv.

${ }^{13}$ David L. Baker, Satu Alkitab Dua Perjanjian, Suatu Studi tentang Hubungan Teologis antara Perjanjian Lama dan Perjanjian Baru (Jakarta: Gunung Mulia, 2006) 209.

${ }^{14} \mathrm{Bd}$. Eugene H. Merrill, A Blibical Theology of The Old Testament - Teologi Alkitabiah Perjanjian Lama. Editor: Roy B. Zuck, Editor Penasihat: Eugene H. Merrill (Malang-Jawa Timur: Gandum Mas, 2005), 30. Mengatakan bahwa bagi orang Kristen, metode yang benar mensyaratkan bahwa Perjanjian Baru dipandang sebagai kesinambungan dari Perjanjian Lama, dan bahwa dua Perjanjian itu saling menerangkan. Ini bukan berarti orang dapat membaca Perjanjian Baru di dalam Perjanjian Lama, melainkan bahwa orang harus mengakui bahwa dua Perjanjian itu merupakan bagian-bagian dari penyataan (wahyu) yang sama yang berasal dari Allah yang satu, dan tidak sesuatu pun dalam Perjanjian Lama yang bertentangan dengan penyataan dari Perjanjian Baru.

${ }^{15}$ Tentang pusat ini Gerhard F. Hasel, Teologi Perjanjian Lama. (Malang, Jawa Timur: Gandum Mas, 2006), 121, menyatakan bahwa masalah pusat ini memainkan peranan penting dan bahkan kadang-kadang menentukan bagi penyajian teologi Perjanjian Lama. Namun juga Hasel mengingatkan orang perlu berhati-hati agar tidak menyerah pada godaan untuk membuat sebuah konsepsi tunggal atau formula tertentu menjadi satu tongkat penemu sumber air yang bersifat abstrak yang dengannya seluruh penyataan dan kesaksian dalam Perjanjian Lama dikombinasikan menjadi satu sistem yang menyatu (Hal. 127). Sasaran akhir dari Teologi Perjanjian Lama ialah menun- 
zaman). Penulis mengikuti pendekatan yang diambil oleh Tremper III yang memberikan pendekatan yang seimbang dengan melihat Kemah Suci sebagai suatu bagian dari penyataan kehadiran Allah dalam metafora Imanuel, ${ }^{16}$ tema yang digenapi di dalam Yesus Kristus sebagai Sang Imanuel itu sendiri (Matius 1:23). Tema kehadiran Allah itu dinyatakan secara berkelanjutan sejak di Taman Eden, dalam mezbah-mezbah, Kemah Perhimpunan, Bait Allah, Kristus, dan gereja sebagai Bait Allah serta Yerusalem Baru. ${ }^{17}$

\section{KEHADIRAN ALLAH DI ANTARA UMATNYA}

Pendirian Tabernakel Musa merupakan inisiatif Allah sendiri di dalam kehendak-Nya yang berdaulat untuk tinggal berdiam di tengah-tengah umat Israel sebagaimana disebutkan dalam Keluaran 25:8-9 "Dan mereka harus membuat tempat kudus bagi-Ku, supaya Aku akan diam di tengah-tengah mereka.").

Hal "berdiam" di antara umat Israel ini mengandung arti Allah menyatakan kehadiran-Nya di tengah-tengah umat-Nya. Tujuan kehadiran dalam Tabernakel ini adalah untuk bersekutu menyatakan penyertaan-Nya dan pemerintahan-Nya ${ }^{18}$ di antara umat Israel (Keluaran 25:21-22; 33:15-17).

Dalam Alkitab hal konsep kehadiran Allah ini juga dinyatakan dalam terminologi "di hadapan Allah" yang berasal dari kata "wajah" (Ibr. panim; Yun. prosopon atau enopion, "di hadapan dari") mengindikasikan kehadiran (presence). Selanjutnya menurut Bromiley ${ }^{19}$ jika dihubungkan dengan Allah, ada tiga pengertian dari kehadiran ini. Pertama, kehadiran secara umum dan mutlak seperti digambarkan dalam Mzm. 139:7. Kedua, kehadiran Allah yang khusus di antara umat-Nya atau di antara bangsa-bangsa yang akan diselamatkan atau akan dihakimi (Kel. 30:14; Nah. 1:5). Hal ini diekspresikan dengan kediaman Ilahi pada Tabernakel atau Bait Allah (Mzm. 48) dan khususnya pada kedatangan Yesus sebagai Imanuel (Mat. 1:23; Yoh. 1:14), kediaman-

jukkan ada atau tidaknya sebuah kesatuan inti yang mengikat berbagai teologi serta tema-tema, konsepsi-konsepsi, dan motif-motif longitudinal. Ini benar-benar merupakan suatu usaha yang berat dan mengandung banyak bahaya (Hal. 183).

${ }^{16}$ Tremper III, Longman, Memahami Perjanjian Lama: Tiga Pertanyaan Penting (Malang: Departemen Litaratur Saat, Cetakan Kedua: 2002), 101-2.

${ }^{17}$ Tremper III, Longman, Memahami Perjanjian Lama: Tiga Pertanyaan Penting.

${ }^{18}$ bd. Gerhard Voss, "Biblical Theology: Old and New Testaments (Pennsylvania: The Banner of Truth Trust), 148.

${ }^{19}$ Geoffrey W. Bromiley, "Presence, Divine" dalam Walter A. Elwell, ed.,"Evangelical Dictionary of Theology, (Grands Rapids, Michigan: Baker Book House, 7th ed.,1990 ), 873. 
Nya berlanjut "di dalam" dan "dengan" murid-murid-Nya oleh Roh Kudus (Mat. 28:20; Yoh. 14:16-17), dan dalam kedatangan-Nya yang final dalam kemuliaan (1 Tes. 2:19). Ketiga, adalah kehadiran Allah di dalam sorga, di mana para malaikat berdiri di hadapan-Nya (Luk. 1:19), di hadapan-Nya tidak ada seorang yang karena kebenaran dirinya sendiri dapat bermegah (1 Kor. 1:29), dari mana segala yang jahat akan dibuang selama-lamanya (2 Tes. 1:9); namun di hadapan-Nya orang percaya akan diperhadapkan tanpa cacat cela oleh kebaikan dari karya Kristus (Yud. 24), dengan demikian menikmati, sebagaimana pemazmur berani berharap, akan kepenuhan dari sukacita (Mzm. 16:11; 73:23-24).

Tabernakel merupakan satu objek yang sangat penting dalam perjalanan umat Israel di padang gurun (Keluaran 25-40). Setelah bangsa itu sampai di Kanaan - tanah yang dijanjikan kepada Abraham dan keturunannya, dan setelah Israel menjadi suatu kerajaan yang kokoh dalam pimpinan DaudSalomo, Tabernakel kemudian digantikan dengan bangunan yang permanen, yakni Bait Allah sesuai dengan kerinduan hati Daud (bd. 2 Taw. 5:5). Jika Bait Suci adalah bentuk permanen dari Tabernakel, maka dapat dilihat hal ini sebagai suatu kontiniuitas. Dalam kitab Wahyu kita melihat pemakaian istilah "kemah" dan "bait" itu dalam satu konteks (bd. Why. 21:3, 22).

Konsep bait suci yang bersifat permanen sebenarnya sudah mulai dikenal sejak masa hakim-hakim, pada masa imam Eli dan Samuel (1 Sam. 1:9). Dalam Bait Suci Salomo, pola dasar dari Tabernakel ini tetap dipertahankan, baik dalam ruangan-ruangan utama (Halaman, Ruangan Suci, dan Ruangan Maha Suci) dan peralatan-peralatan serta tata cara ibadah di dalamnya yang diatur dalam Hukum Taurat. Penting untuk kita ingat bahwa Tabernakel sendiri dibangun menurut contoh Kemah Sejati di Sorga - yang didirikan oleh Allah dan bukan oleh manusia (Ibr. 8:2). Bait Allah seperti Tabernakel dibangun atas inisiatif Allah sendiri. Benar ada bayangan kekekalan di dalamnya sebagai tipologi Kerajaan (pemerintahan) Allah, penebusan, kekudusan, keselamatan yang sempurna, bahkan zaman yang akan datang. Namun bukan berarti berhenti dalam bangunan fisik, selain hal itu tidak memungkinkan lagi sebab objeknya sendiri sudah tidak ada, juga pendekatan secara fisik mempersempit makna kehadiran Allah dan tujuan Allah di dalam pendiriannya.

Terminologi yang dipakai untuk kata yang sepadan dengan Tabernakel ini, dalam Bahasa Ibrani yakni: ōhel mô'êdh (kemah pertemuan), miskhan (kediaman), dan dalam Bahasa Yunani skēnē (kemah). Namun terminologi di atas adalah dalam bentuk kata benda (noun), kita perlu memahami arti kehadiran lebih dalam kaitan dengan kata kerjanya (verb) [Kel. 25:8; 29:45, bd 
Yoh. 1:14] sebagai pernyataan tindakan dan inisiatif Allah untuk berdiam (bertabernakel). Kebanyakan terjemahan Bahasa Indonesia tidak menangkap tekanan yang ada dalam Bahasa Yunani. Kata "diam" terjemahan dari kata skenoo yang merupakan bentuk kata kerja dari "kemah" (skene), Yesus datang dan "berkemah di antara kita." ${ }^{20} \mathrm{Hal}$ ini banyak terjadi dalam pendekatan yang dipakai dalam memahami Tabernakel, berhenti pada eksplorasi terhadap objek, bahan-bahan, alat-alat dan ukuran yang ada pada Tabernakel yang memang dibangun atas petunjuk dari Allah, ada kecenderungan penekanan arti tipologis dan teologis yang bertujuan lebih mulia dari objek Tabernakel dengan segala peralatan dan perlengkapannya. ${ }^{21}$

Tabernakel dibangun dalam konteks perjalanan di padang gurun, dan Bait Allah adalah dalam konteks Tanah Perjanjian, suatu bait yang menetap (permanen) sifatnya.

\section{KEHADIRAN ALLAH DAN PERJANJIAN ANUGERAH}

\section{Kehadiran Allah Dalam Sejarah}

Kehadiran Allah dinyatakan kepada manusia sejak manusia pertama, Adam. Allah menyatakan kehadiran-Nya sebagai tindakan anugerah terhadap manusia yang dicipta serupa dan segambar dengan-Nya. Manusia adalah objek kasih-Nya. Keserupaannya dengan Allah memungkinkannya untuk bersekutu, berkomunikasi dengan Allah. Kemudian manusia itu jatuh dalam ketidaktaatan, jatuh dalam dosa pemberontakan kepada Allah. Namun Allah tetap menyatakan kehadiran-Nya kepada manusia yang sudah jatuh itu (Kej. 3:8). Di sini konsep kehadiran Allah dalam anugerah-Nya yang berdaulat menjadi sangat berarti, bahwa kehadiran-Nya tidak dapat dibatasi oleh apa pun, bahkan oleh dosa.

Kehadiran Allah setelah kejatuhan manusia itu selanjutnya dikaitkan dengan perjanjian keselamatan dalam janji penebusan seperti dalam Kej. 3:15 sebagai proto evangelium setelah Allah menyatakan penghakiman-Nya terhadap Iblis, dan selanjutnya terhadap manusia itu sebab pemberontakan mereka (Kej. 3:15-19 bd. Ibr. 2:16). Anugerah ada di dalam proto evangelium sebagai

${ }^{20}$ Tremper III, Longman, Memahami Perjanjian Lama: Tiga Pertanyaan Penting, 18.

${ }^{21}$ Eugene H. Merrill, A Blibical Theology of The Old Testament - Teologi Alkitabiah Perjanjian Lama. Editor: Roy B. Zuck, Editor Penasihat: Eugene H. Merrill (Malang-Jawa Timur: Gandum Mas, 2005), 97. 
anugerah yang sama sebagai dasar penciptaan manusia, dan terus berlanjut dalam perjanjian anugerah terhadap Nuh dan keturunannya (Kej. 9:8-17), sebagai janji berkat kepada Abraham (Kejadian 12 dan 15), yakni: berkat keturunan (benih), berkat pribadi (memberkatinya dan membuat namanya besar), dan janji untuk menjadi berkat bagi bangsa-bangsa, serta negeri (tanah).

Janji kepada Abaraham itu diwujudkan dengan lahirnya bangsa Israel sebagai umat perjanjian yang ditanam di Tanah Kanaan setelah dilepaskan dari perbudakan Mesir (Kel. 30:1-10). Israel hidup sebagai umat perjanjian, menjadi suatu bangsa. Dan Allah berjanji akan mengokohkan kerajaan itu kepada Daud dan keturunannya jika mereka hidup di hadapan Allah dengan berpegang pada perjanjian (2 Sam. 7:12-16).

Tetapi kemudian bangsa itu juga tidak setia kepada perjanjian. Dan mereka dibuang dari tanah itu di antara bangsa-bangsa. Namun Allah tidak menyesali pilihan anugerah-Nya, setelah Israel yang gagal dalam menaati perjanjian, maka Allah memberikan perjanjian baru seperti dinyatakan kepada Yeremia (Yer. 31:31-34). Perjanjian baru itu digenapi di dalam Kristus, yang menegakkan Perjanjian itu dengan darah-Nya, dengan menjadi Kurban Penebusan di kayu salib. Dialah Benih yang meremukkan kepala si ular oleh kematian dan kuasa kebangkitan-Nya. Dalam Perjanjian Baru itulah, Gereja dibangunkan, menjadi tempat kediaman Allah di dalam Roh (Ef. 2:22). Allah menyatakan kehadiran-Nya di tengah bangsa-bangsa melalui Gereja (Kol. 1:27), ini pun adalah wujud kegenapan janji kepada Abraham untuk menjadikannya berkat bagi bangsa-bangsa, dalam hal ini Gereja sebagai umat Perjanjian Barulah yang menggenapinya oleh kuasa Roh Kudus (Gal. 3:14). Anugerah kasih-Nya meliputi semua orang dan semua bangsa.

Dalam masa Kerajaan 1000 tahun damai hingga Yerusalem yang baru, Kristus dan Allah akan berdiam di tengah-tengah umat-Nya, dan umat itu sendiri berdiam di dalam Tuhan, segenap janji penebusan digenapi sempurna, dan Allah menjadi semua di dalam segala sesuatu (Why. 20:4, 6; 21:22-23; bd. 1 Kor. 15:28).

\section{Kehadiran Allah Untuk Menggenapi Perjanjian-Nya}

Allah itu mahahadir (omnipresence). Kehadiran Allah di sini adalah penyataan pribadi-Nya kepada umat-Nya sebagai Allah Pencipta, Firman yang mencipta dan Roh Allah di mana Ia mau tinggal dan bersekutu dengan umat itu. Kehadiran-Nya itu pada awalnya dinyatakan kepada manusia yang diciptakan-Nya

${ }^{22}$ Paul Enns, The Moody Handbook Of Theology - Buku Pegangan Teologi, (Malang: Literatur SAAT, 2010), 377. 
seturut rupa dan gambar-Nya di Taman Eden. Manusia itu dapat mengenal kehadiran Allah dan dapat berkomunikasi dengan Allah, ${ }^{22}$ sehingga terjadi suatu persekutuan yang intim sebagaimana dicatat dalam Kejadian 1-2. Alkitab tidak mencatat berapa lama keadaan ini berlangsung, di mana persekutuan Allah dan manusia pertama itu terjalin sempurna di Taman Eden. Namun dalam Kejadian 3 kita melihat bagaimana dosa telah memisahkan manusia dari Allah, bahkan dengan bertambahnya dosa, manusia melupakan Allah (Kejadian 4-6).

Kehadiran Allah dinyatakan kepada Adam dan Hawa serta keturunannya, selanjutnya dinyatakan kepada umat-Nya dalam keturunan Enos, berlanjut kepada Nuh dengan kehadiran-Nya yang menghakimi umat manusia yang saat itu sudah bercampur baur dan jatuh dalam kejahatan sejak kecilnya, semua dibinasakan dengan air bah. Hanya Nuh yang mendapat anugerah di mata TUHAN. Kehadiran-Nya kemudian dinyatakan kepada keturunan Sem hingga puncaknya kepada Abraham yang dari padanya lahir suatu bangsa, yakni umat Israel. Setelah keluar dari tanah Mesir, di padang gurun Allah memerintahkan umat itu untuk membangun Tabernakel. Setiap penyataan kehadiran ini tidak lepas dari kurban (Kej. 3:21; 4:4; 8:21-22; Kel. 29:38-46 dst.).

Rencana Tuhan yang kita lihat dalam Tabernakel Musa dan Bait Salomo, adalah tindakan Allah untuk membangun suatu relasi (persekutuan) dengan umat-Nya, dan untuk menguduskan umat pilihan-Nya agar hidup di hadapan -Nya dalam kekudusan dengan hidup menurut hukum dan perintah-Nya,

"Dan di sanalah Aku akan bertemu dengan engkau dan dari atas tutup pendamaian itu, dari antara kedua kerub yang di atas tabut hukum itu, Aku akan berbicara dengan engkau tentang segala sesuatu yang akan Kuperintahkan kepadamu untuk disampaikan kepada orang Israel." (Kel. 25:22)

"Kemudian datanglah firman TUHAN kepada Salomo, demikian: "Mengenai rumah yang kaudirikan ini, jika engkau hidup menurut segala ketetapan-Ku dan melakukan segala peraturan-Ku dan tetap mengikuti segala perintah-Ku dan tidak menyimpang dari padanya, maka Aku akan menepati janji-Ku kepadamu yang telah Kufirmankan kepada Daud, ayahmu, yakni bahwa Aku akan diam di tengah-tengah orang Israel dan tidak hendak meninggalkan umat-Ku Israel." (2 Raj. 6:11-12)

Dalam masa pembuangan Israel memahami hadir-Nya Allah di Bait Suci, tempat Nama TUHAN berdiam. Dan Israel menjadikan Yerusalem di mana Bait Allah berdiri sebagai kiblat dalam doa. Jika mereka bertobat, ada janji Allah mendengar doa itu dan akan membawa mereka kembali dari pembuangan (1 Raj. 8:44-53). Pada masa zaman intratestamental tidak ada satu 
penyataan kehadiran Allah atas umat-Nya dalam bentuk Firman/Wahyu. Allah seperti berdiam diri namun ada janji hingga Ia menyatakan kehadiran-Nya sebagai Malaikat Perjanjian yang dinanti-nanti - Tuhan sendiri hadir di dalam bait-Nya demi keselamatan sisa Israel (Mal. 3:1). Masa itu sesungguhnya adalah masa persiapan bagi kehadiran Imanuel, Mesias bagi umat-Nya pada waktu dan saat yang telah Allah persiapkan (Gal. 4:4).

Dalam Yesus kita tiba pada pemahaman kehadiran Allah sebagai Firman yang menjadi daging - Pribadi Allah sendiri berdiam (hadir) di antara kita (Yoh. 1:14). Kehadiran Mesias di bumi merupakan kegenapan janji terbesar, yakni lahirnya Penebus dari garis keturunan Sem untuk menghancurkan kepala si ular (Kej. 3:15; 9:27).

Gereja adalah buah sulung dari penebusan - Allah di dalam Roh Kudus sekarang berdiam di dalam orang percaya. Kehadiran Roh Allah di dalam Gereja dimulai dengan proses kelahiran baru yang menjadikan seorang percaya menjadi tempat kediaman Allah di dalam Roh (Ef. 1:13-14; 2:22; Yoh. 14:16-17).

Pada masa tribulasi Israel berusaha membangun kembali Bait Allah, dan mengharapkan janji kehadiran Allah. Justru saat itu tampil Antikris yang menuntut penyembahan kepada dirinya dan mengangkat dirinya sebagai Allah (2 Tes. 2:4), sampai Kristus menyatakan kehadiran-Nya untuk membinasakan Antikris dan menyelamatkan sisa Israel. Dan kemudian tiba saatnya kehadiran Allah dinyatakan secara sempurna di tengah-tengah umat-Nya, kemah Allah ada di tengah-tengah manusia dan Ia akan berdiam bersama-sama dengan mereka (Why. 21:3). Tidak akan ada Bait Suci lagi di dalamnya; sebab Allah, Tuhan Yang Mahakuasa, adalah Bait Sucinya, demikian juga Anak Domba itu (Why. 21:22).

\section{SEJARAH KEHADIRAN ALLAH}

\section{Kehadiran Allah Pada Masa Pra-Tabernakel}

a. Rancangan Anugerah Allah yang Kekal (Kej. 1-2)

Dalam Kejadian 1-2 dapat dipahami bahwa Allah adalah Pencipta segala sesuatu, langit dan bumi dengan segala isinya diciptakan-Nya menurut rencana dan kehendak-Nya oleh Firman dan Roh-Nya. Kehadiran Allah itu dinyatakan kepada manusia yang telah diciptakan seturut gambar dan rupa Allah, kehadiran itu dapat dipahami dan dimengerti oleh manusia; manusia dapat berkomunikasi dan menjalin persekutuan dengan Allah secara harmonis. Manusia menjadi "sasaran hadirat pribadi Allah". Hal itu jelas sekali (Kej. 1-2), 
yakni sebelum kejatuhan dalam dosa.

b. Kehadiran Allah dalam Kejadian 3-11, Pasca Kejatuhan Manusia dan Perkembangannya

Tetapi manusia jatuh dalam dosa (Kej. 3). Janji Penebusan dinyatakan untuk menyelamatkan manusia yang sudah jatuh itu (Kej. 3:15). Kehadiran Allah selalu menyertai perjanjian-Nya sebagai tindakan providensia Allah untuk menegakkan perjanjian-Nya dalam kesetiaan-Nya, karena kegenapan perjanjian itu hanya didasarkan atas kesetiaan-Nya pada janji-Nya saja. Bukan kepada perbuatan baik manusia.

Dosa telah merusak keharmonisan persekutuan Allah-manusia, manusia dalam keadaan yang tercemar dan tidak ada kemampuan lagi menghampiri Allah. Manusia dalam bayang-bayang maut. Tetapi Allah menyatakan panggilan-Nya (Kej. 3:9, yang harus kita pahami sebagai panggilan keselamatan kepada manusia pertama yang sudah jatuh dalam dosa).

Manusia yang sudah jatuh itu lalu diusir dari taman Eden supaya ia mengusahakan tanah dari mana ia diambil (3:23). Tetapi kehadiran Allah bagi manusia tidak berhenti, buktinya Hawa mendapat pertolongan dari Allah dalam mendapatkan Kain (4:1). Tentang Kain ini, Hawa bisa jadi mengharapkannya sebagai "benih yang akan meremukkan kepala ular" (3:15), tetapi justru Kain "meremukkan" Habel adiknya dengan memukulnya hingga mati di padang. Alasannya karena persembahannya yang tidak diindahkan oleh TUHAN. Kain dicekam ketakutan akan mengalami hal yang serupa nantinya. Tetapi Allah memberi tanda pada Kain supaya ia jangan dibunuh, tetapi selanjutnya "Kain pergi dari hadapan TUHAN dan ia menetap di tanah Nod, di sebelah timur Eden," di sana ia membangun kota, suatu komunitas tersendiri (4:15-16).

Ada yang hilang dari kelompok Kain ini, yakni hilangnya kesadaran akan kehadiran TUHAN. Kontras dengan komunitas yang ditinggalkannya (4:25-26) yang selalu hidup di hadapan TUHAN dan bagi TUHAN, kesadaran mereka akan pribadi TUHAN tetap terpelihara, bahkan mereka mulai memanggil nama TUHAN. Selanjutnya dalam 5:21-23 kita menemukan tokoh Henokh yang hidup bergaul (berjalan) dengan Allah, lalu ia tidak ada lagi sebab ia telah diangkat oleh Allah.

Ketika anak-anak Allah mengadakan kawin campur dengan kelompok anak-anak manusia (kelompok dari garis Kain), maka kejahatan manusia semakin menyebar di bumi. Saat itu Allah memutuskan penghakiman oleh Roh-Nya 
(6:3), yang akan menghakimi 120 tahun kemudian. Setelah zaman air bah, Nuh bernubuat bahwa kehadiran Allah akan dinyatakan di kemah-kemah Sem (9:27), "ia tinggal [shakan] di kemah-kemah Sem." "Ia" dapat diterjemahkan sesuai konteksnya menunjuk kepada TUHAN sendiri. ${ }^{23}$

Dalam pasal 10 dijelaskan tentang percabangan keturunan Nuh dengan tiga percabangan besarnya. Manusia kemudian membangun Menara Babel (pasal 11). Hal yang menonjol dari persitiwa menara Babel ini, adalah di mana manusia tampaknya kembali melupakan Allah dan berpusat kepada dirinya sendiri, serta berusaha mencari nama bagi dirinya sendiri. Mereka membangun kota dengan zigurat-menara sebagai pusatnya. Allah tidak menjadi pusat manusia lagi.

\section{c. Allah di kemah-kemah Sem - Kejadian 12-50, Terbentuknya Umat Pilihan}

Pada awalnya kehadiran TUHAN dipahami bahwa Allah bertakhta di langit dan memerintah alam semesta, seluruh bumi ada di hadapan-Nya, Ia melihat segala sesuatu, dan tidak ada yang tersembunyi bagi-Nya, sehingga ada konsep Allah turun ke bumi (bd 11:5; 18:21) untuk menghakimi karena Ia mengetahui segala perkara. Ia Mahakudus dan Mahamulia mengatasi segalanya. Pengenalan akan TUHAN yang transenden sebagai Yang Mahatinggi (14:1920), Yang Mahakuasa (17:1) mulai ditemukan dalam Kitab Kejadian, Dia yang turun dari langit (19:24), berbicara dari langit (22:16), tetapi bagi-Nya tidak ada yang mustahil (18:14). Allah memanggil Abraham dari tengahtengah keluarganya 12:1-3 (dari garis keturunan Sem, 11:10-32), dan menjanjikan kepada Abraham berkat bagi kehidupan pribadinya, janji keturunan (bangsa), tanah (negeri), dan menjadi berkat bagi bangsa-bangsa. ${ }^{24}$ Allah selanjutnya meminta ketaatan dari Abraham agar hidup di hadapan Allah dengan "sempurna", "tidak bercela" (17:1).

Allah menyatakan kehadiran-Nya kepada Abraham. Tanda-tanda kehadiran TUHAN dinyatakan dalam bentuk membela Abraham dan keturunannya sebab mereka telah menjadi umat Allah yang akan hidup dalam kebenaran dan keadilan $(18: 19 ; 17: 1)$. Sebaliknya Sodom Gomora harus dibinasakan, sebab mereka tidak hidup dalam kebenaran dan keadilan, tetapi yang berat dosanya, keluh kesah tentang kota itu telah sampai kepada Allah Yang Maha tinggi (18:20-21). Sebelumnya kehadiran Allah yang nyata bagi Abraham dalam

${ }^{23}$ Pemahaman ini mengikuti Walter C. Kaiser, Jr., Teologi Perjanjian Lama (Malang: Penerbit Gandum Mas, 2004), 112-3.

${ }^{24}$ Paul Enns, The Moody Handbook Of Theology - Buku Pegangan Teologi (Malang: Literatur SAAT, 2010), 58. 
teofani, Allah memberi kesempatan baginya untuk mengadakan syafaat tentang nasib penduduk Sodom Gomora, (18:16-33).

Dalam Kitab Kejadian berdoa syafaat ini juga dapat kita lihat dalam diri Ishak yang berdoa bagi Ribka isterinya yang mandul (25:21), juga memberkati Yakub dengan berkat Allah (27:27). Yakub memohonkan berkat bagi keturunannya (48-49), bahkan bagi Firaun (47:10). Doa adalah salah satu cara berkomunikasi dengan Yang Mahatinggi dan Yang Mahakuasa dan memohonkan berkat dari Allah.

Kehadiran Allah Yang Mahatinggi di Sorga dengan malaikat yang turun naik ke bumi, dapat kita temukan dalam pengalaman Yakub ketika melihat tangga yang sampai ke langit, dan malaikat TUHAN turun naik ke bumi (28:10-21). Dalam diri Yakub mulai timbul suatu pemahaman untuk hidup bagi Allah dengan menjadi umat Allah "maka TUHAN akan menjadi Allahku". Hal penyertaan Allah (imanensi Allah) juga mulai dimengerti dari pengalaman Yakub (46:3) dan Yusuf yang disertai oleh Allah (39:3, 21), sehingga karena penyertaan Allah itu segala yang dikerjakannya berhasil. Penyertaan Allah bagi umat-Nya dan yang memelihara umat-Nya adalah wujud kehadiran-Nya di antara umat-Nya (Imanensi Allah).

\section{d. Kehadiran Allah dalam Keluaran 1-24, Kelepasan dan Perjanjian}

Kitab Keluaran didahului dengan kisah perkembangan bangsa Israel di Mesir dan usaha penghambatan perkembangannya oleh Firaun yang tidak mengenal Yusuf. Perhatian TUHAN terhadap kesengsaraan bangsa Israel di Mesir adalah bukti Ia memerintah dari Sorga atas bumi, Ia secara khusus mengingat umat-Nya (2:23-25), Dia yang bertakhta di Surga sekarang turun menyatakan Diri-Nya untuk melepaskan umat-Nya yang menderita (3:8). Ia menyatakan kehadiran-Nya (menampakkan diri, 3:16; 4:5), Dia Allah yang perduli. Kepada Musa Ia menyatakan diri dalam semak duri yang menyala, sebagai Allah ayahmu, Allah Abraham, Allah Ishak dan Allah Yakub (3:6-7). Kehadiran-Nya menguduskan tanah di mana Ia menyatakan kehadiran-Nya. Salah satu ungkapan menghormati kekudusan Allah adalah "menjaga jarak (janganlah datang dekat-dekat) dan menanggalkan kasut" (3:5).

Dalam kehadiran Allah ini lalu TUHAN menyatakan firman-Nya dan maksud-Nya untuk memilih Musa dan mengutusnya, menyatakan penyertaan -Nya, serta melengkapi Musa dengan kuasa dan mukzijat sebagai bukti pengutusanNya, dan Nama Allah "AKU ADALAH AKU"e atau "AKU ADA", "AKULAH 
AKU" (3:14). Sebagai bukti Ia telah menyatakan kehadiran-Nya dan kepeduliaan Allah bagi umat pilihan-Nya yang berada di bawah perbudakan dan penindasan. Bukti kehadiran-Nya adalah tanda-tanda mukzijat, tulah jatuh atas Mesir sebab menolak Israel pergi agar dapat beribadah kepada Allah. Ada perbedaan yang besar dialami oleh orang Mesir dengan orang Israel, jika sepuluh tulah terjadi di Mesir, umat Israel sama sekali terlindung di tanah Gosyen (7-14) ini menyatakan penyertaan TUHAN yang memelihara dan melindungi umat-Nya.

Bahkan TUHAN menunjukkan kuasa-Nya atas alam - laut Teberau terbelah dua sehingga kelihatan yang kering supaya umat Israel dapat menyeberanginya. TUHAN berjalan di depan Israel dalam tiang awan dan tiang api, itulah wujud kemuliaan TUHAN saat itu yang dapat dipandang oleh umat Israel secara kasat mata. Allah ada di situ. Kehadiran yang sungguh nyata. Allah telah turun dalam awan di atas gunung Sinai sebagai Teofani Allah yang begitu dahsyat. Kehadiran Allah itu menuntut pengudusan bagi umat Israel, sebelumnya mereka harus menguduskan diri, mencuci pakaiannya, dan tidak bersetubuh dengan perempuan (19:14-16). Ini mejadi jawaban atas pertanyaan umat itu: "Adakah TUHAN di tengah-tengah kita atau tidak?" (17:7). Tujuan dari semua penampakan TUHAN ini adalah agar takut akan TUHAN ada pada umat Israel, agar mereka jangan berbuat dosa (20:20). Umat Israel sendiri mendengar sendiri Kesepuluh Perintah sebagai hukum bagi Israel, juga hukum ibadat dan hukum kemasyarakatan (20:23) yang harus mereka taati.

Allah mengikat perjanjian dengan umat Israel supaya mereka "sungguhsungguh mendengarkan firman Allah dan berpegang pada perjanjian TUHAN" (19:1-6; 24:7-8). Maka Musa untuk mengingat kehadiran Allah ini kemudian membangun mezbah di kaki gunung itu dengan dua belas tugu sesuai dengan kedua belas suku Israel (24:4-5) dan menyembelih lembu-lembu jantan sebagai korban keselamatan kepada TUHAN.

\section{e. Pendirian Mezbah-mezbah Untuk Mengingat Kehadiran Allah}

Tanggapan terhadap kehadiran Allah dalam Kitab Kejadian selalu diikuti dengan pendirian mezbah lalu diikuti dengan mempersembahkan korban dan memanggil Nama TUHAN (bd 4:3-4, 26; 8:20; 12:7; 13:4, 16; 26:23-25; 28:16 $-19 ; 35: 7)$ atau pemberian nama baru pada satu tempat karena penyataan kehadiran Allah itu $(16: 14 ; 28: 19)$. Mezbah didirikan setelah penampakan atau penyataan kehadiran Allah, bukan sebaliknya (mendahului penyataan kehadiran Allah). Tidak pernah didirikan mezbah tanpa didahului kehadiran atau penampakan Tuhan. Memang hal persembahan korban dapat dilakukan tanpa adanya 
dasar penampakan seperti pengalaman Ayub (Ayub 1:5), juga dalam persembahan Habel, namun dasar persembahan itu adalah iman (bd. Ibr. 11:4, 6), bahwa Allah ada. Bukan untuk menghadirkan Allah. Hidup dalam kebenaran dan keadilan adalah bukti penghargaan dan kesadaran akan kehadiran Allah, untuk hidup di hadapan-Nya, (Kel 20:11; 22:12).

\section{Penyataan Kehadiran Allah dalam masa Tabernakel}

Tujuan dari pendirian Tabernakel adalah agar Allah berdiam (shakan), berhadirat dan bertemu serta memerintah umat-Nya. Pola dari Tabernakel ini berasal dari TUHAN sendiri yang dinyatakan kepada Musa di atas gunung Sinai. Dan yang terutama, rencana ini disertai dengan pemberian dua loh batu, yang berisi Sepuluh Perjanjian sebagai ikatan Perjanjian. Sayangnya di antara rencana dan pelaksanaan pembangunan Tabernakel (32-35) terjadi suatu peristiwa penyimpangan, Israel jatuh dalam penyembahan berhala. Harun telah membuat patung anak lembu emas dan Israel sujud kepadanya dan mempersembahkan korban yang membangkitkan murka Allah. Hal itu terjadi ketika Musa naik ke gunung Sinai selama 40 hari 40 malam. Namun kita melihat bahwa Allah tetap meneruskan rencana-Nya untuk pembangunan Tabernakel, sebab memang Allah sendirilah yang mengambil inisiatif untuk tinggal-berdiam di antara umat Israel.

\section{a. Konsep Kehadiran Allah dalam Keluaran 25-40}

Isi Keluaran 25-40:

- Dalam 25-31 TUHAN memberi perintah pembangunan Tabernakel, Allah memberikan contoh/pola dan rinciannya, diikuti dengan penetapan imam (pelayan) dan para pembangunnya (Bezalel bin Uri bin Hur dan Aholiab bin Ahisamakh serta para ahli), juga bahan-bahan yang diperlukan

- Pasal 32-35 Israel jatuh dalam penyembahan berhala (anak lembu emas)

- Pasal 36-40 adalah pelaksanaan pembangunan Tabernakel.

Allah begitu nyata bagi umat Israel, tetapi juga begitu menakutkan mereka sebab tidak ada seorang yang tahan menghadapi kedahsyatan Allah Yang Mahatinggi dan Yang Mahakuasa yang turun dan menyatakan kehadiranNya di atas gunung Sinai. Karena alasan itu dalam Keluaran 25-40 ini dalam menyatakan kehadiran-Nya, Allah meminta umat Israel membangun Kemah di mana Allah akan berdiam (imanen), supaya Ia akan diam (shakan) di tengah- 
tengah mereka. Dan di atas Tabut Perjanjian, dari atas tutup pendamaian Allah akan bertemu dan berbicara kepada Musa untuk menyatakan perintah-Nya, Dia bertakhta di antara kerubim. Allah yang Maha tinggi - yang transenden, adalah Allah yang imanen di antara umat-Nya.

Pembangunan Tabernakel ini dimaksudkan untuk menyatakan penyertaan Allah dalam kehadiran-Nya di dalam Tabernakel dalam memimpin umat Israel ke Tanah Perjanjian sebagaimana dimaksudkan untuk menggenapi perjanjian-Nya kepada Abraham (Kej. 12:1-2, 7; 15:2-16), bahwa keturunan-Nya akan menduduki tanah Kanaan. Ini menyatakan kasih setia TUHAN dalam menggenapi janji-Nya.

\section{b. Kemah Pertemuan}

Sebelum Tabernakel didirikan, ternyata sudah lebih dahulu Musa mendirikan satu kemah di luar perkemahan tempat ia bertemu dengan Allah yang dinamakan Kemah Pertemuan (Kel. 33:7-11), apabila Musa masuk ke dalam kemah itu, turunlah tiang awan dan berhenti di pintu kemah dan berbicaralah TUHAN dengan Musa, dan TUHAN berbicara kepada Musa dengan berhadapan muka seperti seorang berbicara dengan temannya -suatu kehadiran yang begitu nyata; kemudian kembalilah ia ke perkemahan.

\section{c. Tabernakel Musa}

Hal yang istimewa dalam pembangunan Tabernakel ini adalah karena Allah yang memerintahkan untuk membangunnya dan Allah sendiri memberi polanya dan menggerakkan hati orang-orang untuk membangun dan berswadaya dalam pembangunannya, diwujudkan dengan persembahan-persembahan material Tabenakel, termasuk keahlian, waktu dan tenaga. Tidak seperti pembangunan mezbah-mezbah sebelumnya yang didirikan sebagai jawaban terhadap kehadiran Allah, Tabernakel justru mendahului penyataan kehadiran Allah. Namun hal ini harus dimengerti karena inilah suatu peneladanan (type) akan kehadiran Allah di sorga (Kel. 25:9 bd. Ibr. 8:1-5), dalam kekekalan. Inilah gambaran Kerajaan Allah, pemerintahan Allah yang kekal itu.

\section{d. Kehadiran yang menguduskan}

Tabernakel dibuat dari bahan-bahan yang berasal dari bahan-bahan biasa, dari bahan-bahan sehari-hari yang ada pada umat Israel seperi kain lenan, bulu domba, kulit kambing, dsb. (Kel. 25:2-7; 35:4-29) juga dikerjakan oleh manusia biasa. Namun kehadiran Allah menguduskan semuanya (29:43-46). 


\section{e. Di hadapan Allah}

Semua alat-alat dibuat mengingat kehadiran Allah ini, sehingga alat-alat dalam Tabernakel hanya memiliki artinya di hadapan Allah - dalam mengingat kehadiran Allah. Ada roti di hadapan TUHAN (Kel. 25:30), lampu kandil dinyalakan dan ukupan dibakar di hadapan TUHAN (30:8). Demikian korbankorban yang dibakar di atas mezbah korban bakaran dibakar di hadapan TUHAN (29:40).

Semua bagian-bagian dan semua peralatan - Kemah Pertemuan dan perkakas-perkakasnya, dibangun sesuai dengan contoh yang TUHAN berikan di atas gunung, dan semua diurapi serta dipercik dengan darah untuk menguduskannya, sehingga menjadi maha kudus. Pengurapan dengan minyak ini harus dipandang sebagai suatu upacara pendedikasian (penahbisan) semua alat-alat dan Kemah Tabernakel serta imam-imam bagi TUHAN.

\section{f. Imam-imam yang melayani bagi Allah di hadapan-Nya}

Tentang pelayanan imam-imam keturunan Harun tidak terlepas dari Tabernakel itu sendiri. Merekalah yang dipilih TUHAN dari antara keturunan Lewi untuk melayani di Kemah Suci dan mezbah. Menurut Kel. 19:6, seluruh umat Israel akan menjadi kerajaan imam dan bangsa yang kudus. Imam (kohen) adalah seorang yang melayani. Tetapi secara khusus Allah memilih keturunan Harun untuk melayani di Tabernakel, menjadi "imam bagi-Ku". Imam-imam melakukan pelayanannya di hadapan Allah dan hanya bagi Allah (Im. 8:27, 35; 9:3; 12:7, dst; Kel. 28:30, 41; 29: 23). Ketika Imam Besar Harun masuk ke ruang maha kudus saat hari raya pendamaian (Im. 16), dimaknai sebagai tugas yang dikerjakan di hadapan TUHAN. Ketika Nadab dan Abihu membakar ukupan yang asing, "keluar api dari hadapan TUHAN, lalu menghanguskan keduanya, sehingga mati di hadapan TUHAN." (Im. 10:12). Ini adalah pemikiran tentang penghakiman.

Harun dan anak-anak-anak-Nya menjadi imam bagi TUHAN ("bagi-Ku" Kel. 28:1, 3, 4, 41; 29:1). Dalam Tabernakel dipersembahkan persembahanpersembahan bagi TUHAN (Kel. 29:18, 28, 41, dupa dan minyak urapan hanyalah bagi TUHAN. Ini adalah pemikiran tentang ibadah-pengabdian kepada Tuhan.

\section{g. Pentingnya Dua Loh Batu - Kesepuluh Firman - Inti Perjanjian}

Perintah pembangunan Tabernakel diakhiri dengan pemberian Kesepuluh Firman yang ditulis di atas kedua loh batu. Kedua Loh Hukum ini diperintahkan 
untuk disimpan dalam Tabut Perjanjian. ${ }^{25}$ Sehingga sering disebut bahwa Tabut Perjanjian itu sebagai Tabut Hukum (Kel. 16:34, 25:16, 22, 33, 34, dst). Tabut Perjanjian ini disimpan di dalam Ruangan Maha Kudus dalam Tabernakel.

Kesepuluh Firman ini sangat penting sebab inilah inti Perjanjian Sinai (34:27-28). ${ }^{26}$ Dengan Perjanjian yang berpusat pada Kesepuluh Firman dibangun hubungan persekutuan antara Allah dengan umat Israel sebagaimana dijelaskan dalam pasal 34. Israel harus hidup sesuai dengan Kesepuluh Perintah ini.

Dalam ikatan Perjanjian ini, Allah akan menyatakan perbuatan-Nya, perbuatan-perbuatan yang sungguh dahsyat (34:10), Allah menghalau penduduk tanah Kanaan (34:11), Allah adalah Allah yang cemburu, Allah menuntut kesetiaan supaya Israel jangan hidup dalam penyembahan berhala (34:12-17). Umat Israel harus mengingat kehadiran TUHAN dengan datang ke hadirat TUHAN tiga kali dalam setahun dalam ibadah Hari Raya Tidak Beragi (34:18), Hari Raya Tujuh Minggu (34:22), dan Hari Raya Paskah (34:25). Mereka tidak boleh datang dengan tangan kosong, tetapi dengan membawa persembahan (34:20). Umat Israel benar-benar hidup di hadapan TUHAN dan bagi TUHAN.

\section{h. Tabernakel di Padang Gurun Sebagai Sentral Umat}

Kemah Suci telah menjadi pusat kehidupan orang Israel, saat mereka berkemah, maka Tabernakel ditempatkan di tengah-tengah perkemahan. Ini juga menunjukkan bahwa kehadiran TUHAN menjadi kesadaran mereka setiap hari (Bil. 2:1-2). Demikian saat mereka dalam perjalanan, kemah suci dan Kaum Lewi ada di tengah-tengah caravan dengan Tabut Perjanjian di depan mereka. Mereka mempraktikkan hidup atas pimpinan TUHAN melalui tiang awan dan tiang api (9:15-23). Atas titah TUHAN mereka berkemah dan atas titah TUHAN juga mereka berangkat (9:23). Tabut Perjanjian TUHAN berangkat di depan mereka dan berjalan tiga hari perjalanan jauhnya untuk mencari tempat perhentian bagi mereka (10:33) dengan aba-aba dari Musa.

Secara khusus orang Lewi telah dipilih untuk melakukan pelayanan sepenuh waktu pada Tabernakel. Mereka adalah milik TUHAN sepenuh sebagai ganti anak-anak sulung Israel. Merekalah yang bertanggungjawab dalam membongkar pasang serta mengangkut Tabernakel, demikian dengan segala perawatan dan pelayanannya. Tujuannya supaya orang Israel tidak kena tulah

${ }^{25}$ Di sini Tabut Perjanjian sudah disebut sebelum Keluaran 25:11-22.

${ }^{26}$ Herbert Wolf, Pengenalan Pentateukh, 47. 
apabila mereka mendekat ke tempat kudus (8:18-19). Musa mengunjukkan mereka sebagai persembahan unjukan di hadapan TUHAN, mereka diperdamaikan dan ditahirkan (8:21). Mereka melakukan pekerjaan jabatan mereka di Kemah Pertemuan untuk melayani umat Israel. Pada masa ini ada satu perbedaan antara kaum awam dan kaum Lewi yang sudah dipisahkan dan didedikasikan sepenuhnya hidup dan pelayanan mereka bagi TUHAN. Merekalah yang dipilih untuk mendekat dan melayani di Kemah Pertemuan. Mereka tidak memiliki pusaka (warisan) di tanah terjanji, Allah sendiri menjadi milik pusakanya.

\section{i. Kehadiran Allah Menuntut Pengudusan Perkemahan Israel}

Kehadiran Allah yang dinyatakan di Kemah Pertemuan (Tabernakel) menuntut pengudusan umat Israel sebab Allah itu kudus (Im. 11:44). Pengudusan yang dimaksud adalah sesuai dengan aturan hukum Taurat (15:31). Dalam Kitab Imamat kehadiran Allah dalam Tabernkel itu menjadi sentral kehidupan seluruh umat Israel, baik imamat, perkemahan. Allah melalui Musa menyatakan kehendak-Nya bagi umat Israel (bd. 1:1).

Namun mengherankan dari pengalaman kehadiran TUHAN yang begitu nyata di tengah-tengah Israel dengan segala perbuatan TUHAN yang dahsyat dan ajaib, ternyata tidak mencegah mereka untuk tidak memberontak dan melawan TUHAN, yakni kelompok yang lahir di Mesir. Berulang kali mereka berbuat dosa dan memberontak kepada TUHAN, mereka tidak percaya kepada TUHAN, sehingga generasi yang keluar dari Mesir ini dihukum untuk tidak sekali-kali memasuki tanah Kanaan kecuali Kaleb bin Yefune dan Yosua bin Nun (Bil. 14:11-38) dan generasi baru yang lahir di padang gurun.

\section{Tabernakel Memasuki Tanah Kanaan}

Dalam U1. 30:1-10 Musa menyatakan Perjanjian Tanah (Negeri) kepada umat Israel, mereka harus bertobat, disunat hati sehingga mengasihi Tuhan dengan segenap hati dan segenap jiwa, supaya hidup.

a. Pengajaran Musa Tentang Kehadiran Allah Untuk Mempersiapkan Umat Israel Hidup di Tanah Yang Dijanjikan

Sebelum memasuki tanah Kanaan, Musa - yang tidak diziinkan memasuki tanah Kanaan, memberikan pengajaran yang mempersiapkan umat itu menetap di tanah Kanaan, khususnya dalam hubungan mereka dengan TUHAN. 
Musa menyampaikan kehendak TUHAN tentang satu tempat di mana Allah akan memilihnya sebagai tempat kediaman-Nya untuk menegakkan Nama-Nya (U1. 12:4), di sanalah segala ibadah dipusatkan, segala korban dipersembahkan dan persembahan persepuluhan dibawa dan dinikmati di hadapan TUHAN dengan sukacita (U1. 5-7). Di sanalah perayaan Paskah, Hari Raya Tujuh Minggu bagi TUHAN dan Hari Raya Pondok Daun dirayakan, di tempat yang akan dipilih TUHAN. Tiga kali dalam setahun setiap orang laki-laki harus menghadap hadirat TUHAN dengan membawa segala persembahan.

Kehadiran TUHAN menjadi sentral, di tempat yang Allah pilih, di sanalah pengadilan tertinggi, tempat pelayan TUHAN dan hakim (17:12). Ketika mereka mengangkat raja di tanah yang TUHAN karuniakan, maka raja yang TUHAN pilihlah yang mereka angkat, raja yang yang takut akan TUHAN dengan berpegang pada segala hukum dan perintah menurut kitab yang ada pada imam-imam orang Lewi (17:14-20). Dalam apa yang kita baca dalam Kitab Ulangan, bahwa ketaatan kepada Hukum Allah sangat ditekankan dan menjadi sentral kehidupan umat Israel, sikap taat mendatangkan berkat, dan ketidakta-atan mendatangkan kutuk (27-28). Hal ini tidak lepas dari perjanjian dengan Allah dengan ikatan taat. Perjanjian Tanah bagi Israel diteguhkan (30:1-10).

\section{b. Penyimpangan-penyimpangan Berupa Pemberhalaan Tabut Perjanjian dan Efod,} Pemahaman Yang Salah Tentang Kehadiran Allah

Dalam Ul. 29:10, 15, 18 di tanah Moab perjanjian di Horeb dibaharui di hadapan TUHAN, maka sikap berpaling meninggalkan TUHAN Allah adalah dengan pergi berbakti kepada allah bangsa-bangsa kafir. Setelah diam di tanah perjanjian pada zaman Hakim-hakim umat Israel beribadah kepada para Baal dan berbalik dari TUHAN (Hak. 2:10-12).

Mungkin karena melihat latar belakang kemenangan Israel dulu dalam peperangan menghadapi musuh, maka umat Israel memiliki konsep pemikiran bahwa kehadiran Tabut Allah sebagai bukti kehadiran-Nya di tengah-tengah umat TUHAN (1 Sam. 4:3), suatu pemahaman kafir seperti dipahami oleh orang Filistin sendiri ("Allah mereka telah datang ke perkemahan itu"), dan itu selama 400 tahun sebelumnya tidak pernah dipraktekkan demikian (1 Sam. 4:3-8) dan ternyata Israel dapat dikalahkan. Tangan TUHAN tidak menaklukkan mereka seperti dulu tangan TUHAN menaklukkan Mesir. Tabut Perjanjian pun dirampas dan dibawa ke Filistin. Tetapi apa yang terjadi di Filistin?

Ternyata tangan TUHAN menekan bangsa Filistin dengan kuat, berhala Dagon jatuh dengan mukanya ke tanah di hadapan tabut TUHAN. Karena kehadiran Tabut Perjanjian, berbagai tulah mereka alami sehingga 
mereka berusaha mengembalikan Tabut Allah Israel ke tempatnya semula dan menujui Bet Semes (6:2). Allah menentang berhala. Tetapi ternyata tidak hanya Tabut, baju Efod juga diberhalakan oleh Gideon (Hak. 8:27; 17:5; 18:14).

\section{c. Akhir Perjalanan Tabernakel di Yerusalem dan Bait Salomo Didirikan}

Dalam masa Yosua tempat kudus TUHAN adalah di Silo (Yos. 18:1) sampai zaman hakim Samuel empat ratus tahun lamanya. Hingga Tabut Perjanjian direbut dan dibawa oleh orang Filistin dalam sebuah pertempuran (1 Sam. 4-6) dan kemudian dikembalikan ke Israel. Dalam 1 Sam 1:7; 3:3 diketahui Kemah Suci sudah berusia kurang lebih 400 tahun, di Silo disebut rumah Allah (sifatnya permanen), bukan lagi berupa kemah. Ada jejak dari perkakas Tabernakel di Nob (2 Sam. 21:1-6). Hingga kisah Tabernakel Musa berakhir dalam 2 Taw. 5:5 ketika Bait Salomo didirikan.

\section{Kehadiran Allah dalam Bait Suci}

\section{a. Janji Keturunan - Dinasti}

Kehadiran Allah dalam Bait Suci Salomo harus kita mengerti alam konteks umat perjanjian Allah (1 Raj. 8:20-21; 1 Taw. 17:9-14) yakni untuk mengokohkan perjanjian dengan mengokohkan kerajaan bagi Daud dan keturunan-Nya (Kej. 12:2 bd 2 Raj. 6:11-12).

\section{b. Tabut Perjanjian pada masa Saul}

Tabut Perjanjian sama sekali tidak mendapat perhatian, sehingga tetap berada Kiryat Yearim di rumah yang di atas bukit, di rumah Abinadab. Dan Eleazar anaknya mereka kuduskan untuk menjaga tabut itu (1 Sam. 7:1). Hingga kemudian tampilnya Daud yang berinisiatif membawa Tabut itu ke Yerusalem (2 Sam. 6:1-2). Hanya dalam cara membawa Tabut itu mereka mempergunakan caranya orang Filistin, menjadi sebab kematian Uza (6:6-7). Selama beberapa waktu, kehadiran Allah di atas Tabut hanya dinyatakan dalam bentuk perbuatan-perbuatan Allah yang menghukum, sehingga mendatangkan rasa gentar, hingga Daud menjadi marah, dan Daud menjadi sangat takut kepada TUHAN $(6: 8,9)$. Tetapi pemikiran itu berubah ketika Daud mendengar rumah Obed Edom tempat tabut itu tinggal begitu diberkati TUHAN $(6: 11,12)$. Dengan demikian apa yang TUHAN nyatakan dalam Taurat diingatkan 
kembali: kutuk atau berkat, tergantung sikap seseorang di dalam menghargai Taurat TUHAN.

\section{c. Kehadiran Allah di Bait Salomo, berperan sebagai Kiblat}

Berbeda dengan pembangunan Tabernakel yang merupakan inisiatif dari Allah, maka pembangunan Bait Allah yang permanen dibangun atas inisiatif Daud. Sekalipun kalau kita lihat bahwa sudah ada kecenderungan pembangunan bait Allah yang permanen pada zaman Imam Eli (1 Sam 1:7). Allah memperkenan rancangan Daud, tetapi hal pendiriannya akan dikerjakan oleh anak Daud. Suatu kedaulatan TUHAN atas bait-Nya dinyatakan. Sekaligus merupakan kisah akhir dari perjalanan Tabernakel Musa [mishkan], (2 Taw. $5: 5)$.

Dalam pembangunan Bait Allah ini dihubungkan dengan pengokohan dinasti/takhta dari keturunan Daud (2 Sam. 1:1-17; 1 Taw. 17:15). Ada pekembangan pemahaman tentang bait Allah ini, seperti dikatakan oleh Salomo, benarkah Allah hendak diam di atas bumi, bahkan langit yang mengatasi langit sekalipun tidak dapat memuat TUHAN, terlebih lagi bait yang Salomo dirikan (1 Raj. 8:1). Sorga adalah kediaman-Nya yang tetap (1 Raj. 8:39, 49). Bait Allah adalah tempat kediaman Nama TUHAN, menjadi rumah doa (1 Raj. 8:29-30). Juga hal pengampunan dosa ketika datang ke mezbah menjadi sesuatu yang menonjol di dalam fungsi Bait Allah, ay. 31-51). Kesadaran akan hadirat TUHAN dinyatakan dengan ungkapan "di hadapan TUHAN", (ay. 22-25). Sekarang Bait Allah mejadi kiblat doa. Saat menghadapi kekeringan, kelaparan, wabah, dsb. mereka akan didengarkan ketika datang bertobat da berbalik serta berdoa (ay. 26-31). Bahkan orang asing jika datang karena Nama TUHAN dan berdoa di rumah ini, (ay. 32-33) mereka akan didengar; rumah TUHAN menjadi rumah doa bagi bangsa-bangsa. Ketika Israel umat TUHAN keluar berperang, dan mereka berdoa dengan berkiblat ke kota dan ke bait tempat Nama TUHAN tinggal, Allah akan mendengar dari Sorga dan Allah memberi keadilan (ay. 44-45). Jadi, menjadi berkat bagi bangsa-bangsa yang dinyatakan kepada Abraham mulai digenapi di dalam pembangunan Bait Allah ini. Yerusalem tempat bait Allah dibangun sekarang juga menjadi kiblat doa. Bait itu adalah kediaman dari Nama TUHAN. Jika mereka berdosa kepada TUHAN, dan mereka tertawan, lalu berbalik dengan sungguh-sungguh dan berdoa mengarahkan diri ke Bait Allah di Yerusalem ini, maka Allah akan memberi keadilan, membuat umat-Nya itu menjadi kesayangan sebab merekalah umat Allah sendiri, dan milik kepunyaan-Nya (2 Taw. 6:12-42). Pembangunan Bait Salomo melibatkan bangsa-bangsa lain, 
seperti Hiram raja Tirus yang mengirim penebang-penebang kayu untuk menebang kayu aras Libanon (2 Raj. 5; 2 Taw. 2:1-18).

\section{d. Israel Yang Menyimpang dari Allah dan Dibuang dari Tanah Perjanjian}

Dalam U1. 29:10, 15, 18 sikap berpaling meninggalkan TUHAN Allah adalah dengan pergi berbakti kepada allah bangsa-bangsa kafir. Itulah yang dilakukan Salomo di hari tuanya, menyimpang dari pada TUHAN dengan mengikuti allah-allah lain (1 Raj. 11:3). Hal ini menyebabkan dikoyakkannya kerajaan itu, sebagian diserahkan kepada hamba Salomo, sehingga kita mengenal Israel Utara dan Israel Selatan.

Dalam 1 Raj. 12:25-33 Yerobeam kembali jatuh dalam penyembahan lembu emas yang terlarang seperti umat Israel di padang gurun. Inilah awal penyimpangan sebagai suatu bangsa yang mengakibatkan pada akhirnya Israel Utara dibuang dari tanah itu.

Dalam 2 Raj. 17:7-23 nyata bahwa Israel tidak menghargai hadirat TUHAN dan tidak berpegang pada perjanjian sebagai umat Allah untuk menaati-Nya, akibatnya mereka dibuang dari hadapan TUHAN, Israel diangkut ke Asyur sebagai tawanan.

Apa yang dilakukan raja-raja Yehuda mengikuti jejak raja-raja Israel Utara dan bahkan tidak bertobat dari dosa-dosa Salomo membangun bukitbukit pengorbanan, dengan puncaknya adalah dosa Manasye yang telah membawa masuk dan mendirikan patung-patung berhala, mezbah-mezbah bagi tentara langit ke dalam pelataran TUHAN, ini adalah puncak pemberontakan suku Yehuda sehingga tidak mungkin lagi ada pengampunan (2 Raj. 24:1-4). Tindakan Yosia menghapuskan segala penyembahan berhala ini kemudian hanya menunda pembuangan bangsa Yehuda yang sudah pasti (2 Raj. 23). Mereka dijauhkan dari hadapan-Nya karena dosa-dosa Manasye (2 Raj. 24:3). Sebagaimana diketahui kemudian Yerusalem diruntuhkan, Bait Allah dinajiskan dan dibakar. Segala perabotannya dibawa ke Babel (2 Taw. 36:11-21).

\section{e. Kehadiran Allah Saat Israel di Pembuangan}

Dalam 2 Taw. 36:21 disebutkan juga sebab Israel telah melalaikan Sabat, dan untuk itu mereka akan dibuang selama dilalaikannya tahun-tahun sabatnya, hingga genaplah 70 tahun. Dan kemudian ditandai dengan kembalinya sebagian bangsa Yehuda dari pembuangan. 
Kepada Yehezkiel Allah menyatakan kehadiran-Nya (Yeh. 1) di Babel, di negeri orang Kasdim, di tepi sungai Kebar. Kehadiran TUHAN yang memiliki hubungan dengan umat perjanjian-Nya tetap nyata di dalam pembuangan, Allah masih memberi karunia-karunia kepada pemuda-pemuda Yehuda (Dan 1:17), Ia menyatakan kehadiran-Nya saat Sadrakh, Mesakh, dan Abednego dibuang ke dalam perapian yang menyala-nyala akibat mempertahankan imannya, Allah menyatakan rahasia mimpi (pasal 2), kehadiran-Nya dilihat oleh Nebukadnezar seperti Seorang Anak Dewa (pasal 3), bahkan dalam hukuman-Nya yang nyata kepada Raja Belsyazar akibat tidak menghargai kekudusan Allah (pasal 5). Daniel mengalami pembelaan Allah ketika dilempar ke gua singa, Allah mengutus malaikat-malaikat-Nya mengatupkan mulut singa yang lapar (pasal 6). Kita melihat kehadiran Allah dalam penglihatanpenglihatan Daniel, bahkan lewat kehadiran para malaikat yang Allah utus (pasal 7).

Allah mendengar doa dari umat-Nya yang berdoa menghadap hadirat-Nya (Yerusalem sebagai kediaman Nama TUHAN) yang mau berbalik dan bertobat dengan berpegang kembali pada perjanjian yang disampaikan oleh Musa (Neh. 1:4-11). Allah berdaulat dan berkuasa membawa Israel kembali kepada negeri perjanjian yang dijanjikan-Nya. Di pembuangan Yerusalem menjadi kiblat ketika umat-Nya berdoa, seperti dilakukan oleh Daniel (Dan 6:11).

Allah tetap menyatakan kesetiaan-Nya terhadap perjanjian-Nya untuk diam di Yerusalem dengan menggerakkan raja-raja dari bangsa-bangsa lain untuk membawa Yehuda kembali (Ezra 1:1-5) dan membangunkan kembali Bait Allah (Ezra 3, 6; Hag. 1-2). Janji yang sangat menghiburkan tentunya adalah janji kehadiran Allah yang terus menerus terhadap umat Israel, bahwa "Roh-Ku tetap tinggal di tengah-tengahmu," (Hag. 2:6). Sehingga Israel percaya bahwa mereka juga tidak akan lenyap (Mal. 3:6).

\section{Kehadiran Allah Dalam Masa Intratestamental}

Ini adalah masa-masa seusai Israel yang telah menyimpang dan dibuang dari tanah perjanjian itu mulai dibawa kembali pulang ke tanah perjanjian. Namun tidak semua mereka kembali ke tanah perjanjian, tetapi hidup dalam diaspora di negeri-negeri asing. Mereka di tanah persebaran membangun sinagoga-sinagoga yang berkiblat ke tanah perjanjian dalam ibadahnya seperti dilakukan Daniel (Dan 6:11).

Pada masa ini Bait Allah yang telah diruntuhkan telah dibangun kembali, seperti kita kenal sebagai bait Allah yang dalam masa Yesus yang disebut bait Herodes. Hanya saat ini tidak terdengar lagi Tabut Perjanjian. Tetapi kita 
menyadari bahwa kehadiran Allah di dalam Bait-Nya adalah hal yang tidak terbantahkan seperti Yesus ungkapkan kemudian (Mat. 23:21). Kepada nabi Hagai yang hidup mendahului masa kesunyian ini, Allah berjanji bahwa RohNya tidak akan meninggalkan Israel (Hag. 2:6).

Masa antar perjanjian ini (400 tahun sebelum Kristus) adalah masa kesunyian/kesenyapan di mana kehadiran Allah dalam Firman yang disampaikan lewat para nabi tidak pernah terdengar lagi. Namun ini adalah masa persiapan untuk kehadiran Mesias, yang akan tiba-tiba memasuki Bait Allah (Mal. 3:1). Inilah saat Allah dalam kesenyapan mempersiapkan panggung sejarah dunia, bagi datang-Nya Mesias, Anak Allah yang hidup (Gal. 4:4).

\section{REFLEKSI TEOLOGIS KEHADIRAN ALLAH DALAM TABERNAKEL}

Tindakan kehadiran Allah bagi umat perjanjian-Nya dalam Tabernakel berada dalam konteks rencana keselamatan atas umat pilihan-Nya yang telah ditempatkan-Nya di hadapan-Nya supaya mereka hidup bagi Dia dalam ikatan perjanjian dalam ketundukan kepada pemerintahan-Nya (Theokrasi). Perjanjian itu mengikat bahwa TUHAN menjadi Allah atas umat-Nya - yakni umat yang mau taat dengan hidup di dalam keadilan dan kebenaran, bahkan dalam kekudusan - sebagai umat yang dikhususkan bagi Allah.

Kehadiran ini sudah dinyatakan dalam Perjanjian Lama sejak taman Eden, tetapi dosa telah merusak tatanan yang sangat ideal ini. Kerusakan itu adalah pada sisi manusia, yang tidak memiliki kemampuan lagi menanggapi kehadiran Allah. Tetapi kehadiran Allah tidaklah dapat dibatasi oleh dosa sekalipun itu bertentangan dengan karakter Allah yang kudus. Ketika Dia hadir dalam kedaulatan-Nya, maka pada-Nya ada penghakiman sekaligus belaskasihan.

Pada umat Israel kehadiran-Nya dinyatakan-Nya sebagai kehadiran (berdiam) "di antara kita", (Kel. 25:8; 29:45) hingga pada umat Perjanjian Baru suatu kehadiran (berdiam) "di dalam kita" oleh Roh Kudus (Yoh. 14:1617), dan pada akhirnya (di Yerusalem Baru) kehadiran Allah dinyatakan "Ia akan diam bersama-sama dengan umat-Nya" (Why. 21:3). Konsep tentang pemikiran kehadiran Allah diam "di antara kita", "di dalam kita", dan "bersama dengan kita" membawa pada pemahaman bahwa umat itu senantiasa ditempatkan "di hadapan Allah" di mana "segala sesuatu terbuka (tidak ada 
yang tersembunyi) di mata TUHAN."

Dalam arti positif dengan kehadiran Allah (hidup di hadapan-Nya) umat itu hidup "bagi Allah" sebagai umat yang kudus. Dengan demikian mengandung juga unsur "ibadah, pengabdian" (Kemah Suci sendiri dibangun adalah bagi-Ku [bagi Allah])" (Kel. 25:8) karena Dia adalah Allah, maka segala sesuatu telah diciptakan bagi Dia dan oleh Dia saja (Ibr. 2:10). Selanjutnya adalah unsur penghakiman (Yes. 3:13-15). Konsep-konsep ini terjalin dalam suatu kesatuan seperti dalam Mazmur 139. Hal itu jugalah yang terjadi di Taman Eden setelah kejatuhan manusia pertama, ketika Allah menyatakan kehadiran -Nya, maka Iblis dihukumnya tetapi manusia mendapatkan belaskasih-Nya. Kemudian kehadiran itu dinyatakan dalam Tabernakel dan dalam Bait Allah dengan kemuliaan Shekinah, selanjutnya di dalam Perjanjian Baru dalam inkarnasi Kristus dan berdiamnya Roh Kudus di dalam Gereja, hingga pada akhirnya nanti pada akhir zaman (eschaton).

Kehadiran Allah dalam Tabernakel bukan berarti mengurangi makna kemahahadiran-Nya, tetapi inilah kehendak-Nya untuk bersekutu, menyertai umat-Nya dan tinggal di tengah-tengah umat-Nya dan menyatakan (mengomunikasikan) segala maksud dan rencana-Nya melalui Firman-Nya.

Setiap kali kehadiran itu dinyatakan kepada umat-Nya, selalu kemuliaan Allah menyertainya, sampai dalam zaman Gereja, sehingga perjalanan iman orang percaya adalah perjalanan yang sangat berharga, perjalanan dari kemuliaan kepada kemuliaan (2 Kor. 4:18). 